\title{
Aim-Oriented Empiricism and the Metaphysics of Science
}

\section{Nicholas Maxwell}

\begin{abstract}
Over 40 years ago, I put forward a new philosophy of science based on the argument that physics, in only ever accepting unified theories, thereby makes a substantial metaphysical presupposition about the universe, to the effect it possesses an underlying unity. I argued that a new conception of scientific method is required to subject this problematic presupposition to critical attention so that it may be improved as science proceeds. This view has implications for the study of the metaphysics of science. The view has however been ignored by recent contributions to the field. I indicate broader implications of the view, and consider reasons why the view has been neglected.
\end{abstract}

\section{Introduction}

Most scientists and philosophers of science take for granted some version of standard empiricism - the doctrine that a scientific theory, in order to be accepted, must satisfy two requirements: it must be sufficiently empirically successful; and it must be sufficiently simple, unified or explanatory. The crucial tenet of standard empiricism is however that no substantial thesis about the universe - or about the phenomena - can be accepted permanently as a part of scientific knowledge independently of empirical considerations, let alone in contradiction with them.

In 1974, I put forward a new philosophy of science - a new view about what are and what ought to be the aims and methods of science - which contradicts standard empiricism. This view, which I called aim-oriented empiricism (AOE), holds that there are problematic metaphysical assumptions inherent in the aims of science. In order to improve these assumptions, we need to represent them in the form of a hierarchy, assumptions becoming less and less substantial, more and more nearly such that their truth is required for science to be possible at all, and thus less and less problematic, as we ascend the hierarchy. Two of these assumptions, at the top of the hierarchy, are accepted permanently as a part of scientific knowledge independently of empirical considerations; an assumption lower down in the hierarchy is open to revision but contradicts currently accepted physical theory. These two points ensure that AOE clashes with standard empiricism. Assumptions and associated methods high up in the hierarchy form a relatively unproblematic, stable framework within which much more substantial and problematic assumptions and associated methods, low down in the hierarchy, can be improved as science proceeds. Science improves its methods in the light of improving theoretical knowledge. There is something like positive feedback between improving scientific knowledge and improving assumptions and associated methods, a feature of scientific method which helps explain the explosive growth in scientific knowledge. ${ }^{1}$

The implication of this work, spelled out further in subsequent publications, ${ }^{2}$ is that speculative and critical metaphysical thinking becomes an integral part of science itself - in particular of theoretical physics. The topic of the metaphysics of science is transformed.

Since my publications in this field, there has been an astonishing burst of activity in philosophy of science devoted to the topic of the metaphysics of science. Paper after paper, book after book, have been published. But, astonishingly, this recently burgeoning body of literature completely ignores my earlier work on precisely the same topic: the metaphysics of science. Furthermore, even though this earlier work argues we need to transform the whole field so that imaginative and critical thinking about metaphysical possibilities for science is 


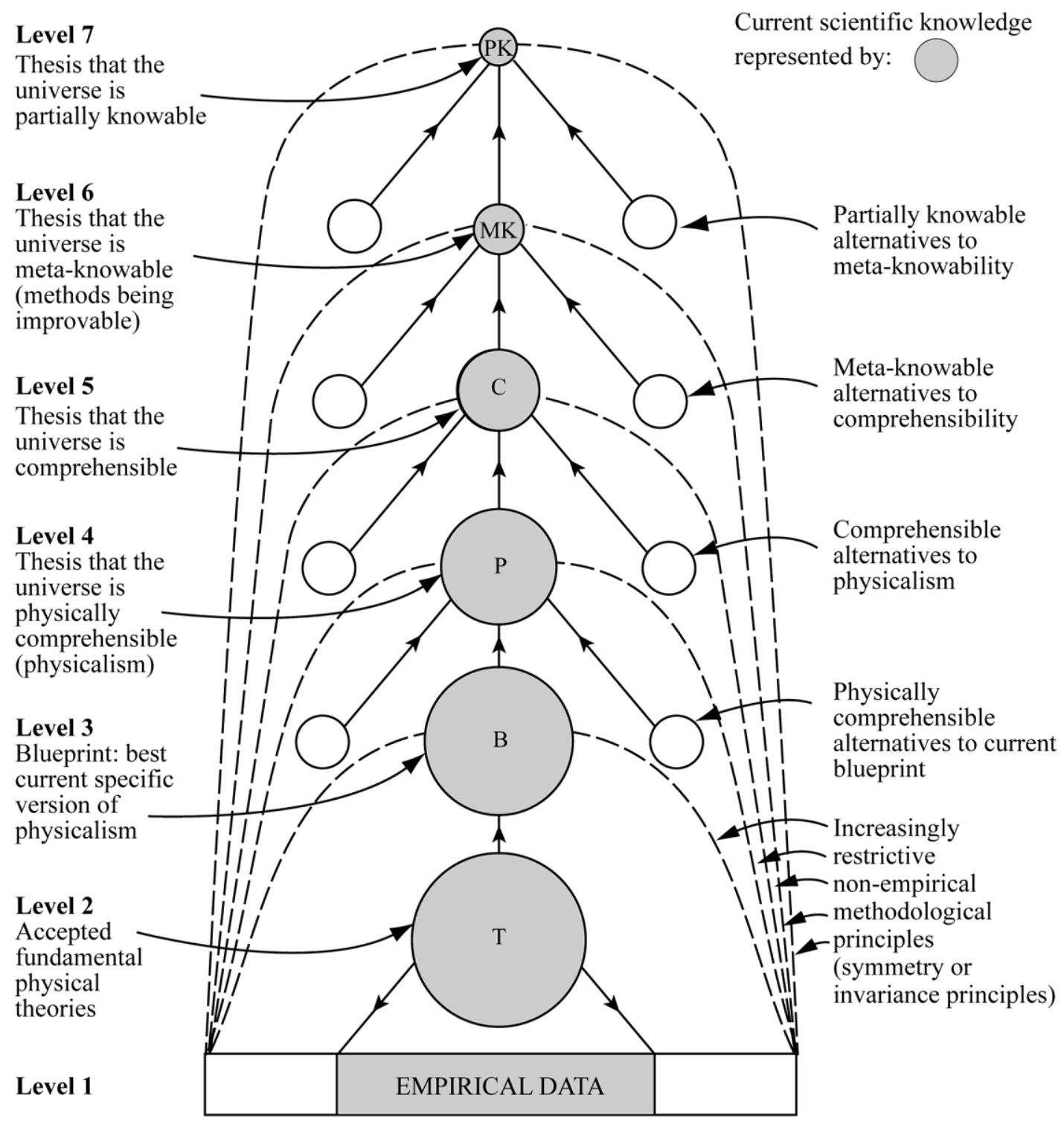

Figure: Aim-Oriented Empiricism

conducted as an important, integral part of science itself, all this is ignored. Ignored too is later work on AOE, elaborating my pre 2007 work.

In what follows, I spell out the implications of AOE for the metaphysics of science. I go on to indicate how later work suffers from ignoring my earlier work on the subject. I then indicate implications of AOE, not just for science, but more broadly for academic inquiry as a whole, and its capacity to help humanity make social progress towards a better world. I conclude by considering, briefly, why work on the metaphysics of science has ignored my earlier work on AOE.

\section{Implications of Aim-Oriented Empiricism (AOE)}

Aim-oriented empiricism (AOE) has been expounded and argued for in great detail in a number of places in the literature (see notes 1 to 3 ); here I will be brief.

AOE emerges from the following considerations. In physics, only unified fundamental physical theories are ever accepted, even though endlessly many empirically more successful, disunified rival theories are always available. ${ }^{3}$ This persistent acceptance of unified theories 
only, when endlessly many empirically successful disunified rivals are available means that physics makes a big, highly problematic, and at present implicit, metaphysical assumption about the nature of the universe: it is such that all disunified theories are false. Some kind of unified pattern of physical law runs through all physical phenomena. The universe is such that some as-yet undiscovered physical "theory of everything" is both unified and true.

This metaphysical assumption of underlying unity is, however, profoundly problematic. In the specific form in which it is accepted, at any stage in the development of physics, it is almost bound to be false. A glance at the history of the metaphysics of physics reveals that we have changed our minds a number of times. In the $16^{\text {th }}$ and $17^{\text {th }}$ centuries the universe was held to be made up of rigid corpuscles that interact only by contact. This gave way to the idea that it is made up of point-particles that have mass and are surrounded by a rigid, spherically symmetrical, centrally directed field of force, alternatively repulsive and attractive as one moves away from the point-particle. This became the view that charged particles are embedded in a unified field, interactions moving through the field with finite speed. This became the view that there is only the field, interacting with itself, particles being especially intense regions of the field. And this became the view that the world is made up of quantum entities (whatever exactly they may be), which in turn became the view, current today, that the world is made up of tiny, closed quantum strings in ten or eleven dimensions of spacetime. All these theses, from the 17th century corpuscular hypothesis to the 21 st century string theory, are metaphysical theses in something like Karl Popper's sense that they are empirically unfalsifiable. ${ }^{4}$ They are all too imprecise to issue in specific empirical predictions. In this respect, they are quite different from physical laws and theories that go to make up the content of theoretical physics: Newtonian theory, quantum theory, and the rest. These metaphysical theses have, however, exercised an influence over theoretical physics in influencing both the search for new physical theories, and the acceptance of physical theories.

It is important, for physics, that a good choice of metaphysics is made, since whatever choice is made will influence what theories physics seeks to develop, and what theories it accepts. A good choice will promote scientific progress, while a bad choice will stultify it. At the same time, granted that we are concerned with the ultimate nature of the universe, the domain of our ignorance, we are almost bound to make a choice that is false, and which will, as a result, almost certainly at some point obstruct the advance of theoretical physics. Here, above all, we need to proceed in such a way that we make the best possible choice of metaphysics that we can. The way to do that is to make, not just one metaphysical assumption, but a whole hierarchy of assumptions - as I have already indicated in section 1: see figure. Assumptions at levels 7 and 6 are accepted permanently, even though we have no reason to believe them to be true, on the grounds that making these assumptions can only help, and cannot harm, the scientific task of improving knowledge (whether these assumptions are true or false). As we descend the hierarchy, from 5 to 3 , assumptions become increasingly substantial, and thus increasingly likely to be false and in need of revision. At these levels, as I indicated in section 1, we accept that assumption which (a) accords best with assumptions above in the hierarchy, and (b) is associated with the most empirically progressive scientific research programme (at levels 2 and 1), or promises to be so associated. Those empirically testable theories are accepted which (a) accord best with assumptions at levels 3 and 4, and (b) are the most empirically successful.

In my publications I have demonstrated in some detail that the above considerations in support of AOE, have the following substantial implications:-

1. AOE needs to be put into scientific practice in order to strengthen the intellectual integrity and success of science. The outcome would be a new, improved kind of 
science, more rigorous and of greater intellectual and humanitarian value. Science itself would change, and be improved. ${ }^{5}$

2. All versions of standard empiricism are untenable. ${ }^{6}$

3. The relationship between science and the philosophy of science would be transformed. Philosophy of science would become an integral part of science itself. ${ }^{7}$

4. AOE reveals that science has already established, as a part of theoretical knowledge, the metaphysical thesis physicalism (as I have called it, the level 5 thesis of the diagram). ${ }^{8}$

This asserts that the universe is physically comprehensible - that is, it is such that there is a yet-to-be-discovered physical "theory of everything" that is unified and true.

5. Physicalism, though incompatible with current knowledge in physics at the level of theory (general relativity plus the standard model), is nevertheless one of the most secure items of theoretical knowledge in physics that we have, so secure that any theory which clashes too severely with it is rejected, whatever its empirical success may be. ${ }^{9}$

6. Scientific method is revealed to have a hierarchical structure corresponding to the hierarchical structure of metaphysical presuppositions, or aims, of science. It is this hierarchical structure that makes it possible for methods, high up in the structure, to control evolving methods, low down in the structure. ${ }^{10}$

7. AOE carries the implication that orthodox quantum theory, or indeed any version of quantum theory that is about the result of measurement only and not, in the first instance, about quantum systems as such, is seriously defective (it lacks unity). ${ }^{11}$ A fully microrealistic version of quantum theory, probabilistic or deterministic, needs to be developed. ${ }^{12}$

8. The so-called "pessimistic induction" is no grounds for pessimism at all. The way in which physics has proceeded, from Newton to today (even though from one false theory to another), is just the way physics would proceed were it to be making splendid progress (and AOE is correct). ${ }^{13}$

9. AOE facilitates the progressive improvement of the metaphysics of science in the light of (a) a priori, and quasi a priori considerations (e.g. having to do with unity), and (b) considerations that have to do with empirical fruitfulness - the extent to which the metaphysical thesis in question has led to an empirically progressive scientific research programme. ${ }^{14}$ According to AOE, science improves its metaphysical assumptions and associated methods as it improves its knowledge: there is something like positive feedback between them (which helps account for the explosive growth in scientific knowledge). The metaphysics of physics becomes an integral part of physics itself.

10. AOE solves the problem of induction - and is required to solve the problem. ${ }^{15}$

11. The problem of what it means to say of a physical theory that it is unified is solved within the framework of AOE. This solution provides the means to partially order physical theories with respect to unity. Unity and simplicity are sharply distinguished. ${ }^{16}$

12. AOE solves the problem of why physics is justified in preferring unified theories to disunified ones. ${ }^{17}$

13. The problem of verisimilitude is solved within the framework of AOE. ${ }^{18}$

14. AOE provides physics - and science more generally - with a fallible, non-mechanical (i.e. non-algorithmic) but rational method for the discovery of good new theories. ${ }^{19}$

15. AOE is a synthesis of, and a great improvement over, the views of Popper, Kuhn and Lakatos. $^{20}$

16. Instrumentalism (or constructive empiricism) is untenable because it cannot do justice to the requirement of unity. Unity demands scientific realism. ${ }^{21}$

The upshot of all this is that a revolution is required in the way we engage in the topic of the metaphysics of science. The metaphysics of physics, in particular, becomes an important, 
integral part of physics itself; it needs to proceed within the context of AOE, and would amount to the development of elements of AOE (especially at level 3).

\section{Failure of Recent Work in the Metaphysics of Science to take AOE into Account}

I now attempt to indicate just how widespread is the failure of relatively recent work on the metaphysics of science to take AOE into account, and I do what I can to highlight inadequacies in this work that stem from this failure.

I have looked at the work of some 53 authors published during the years 2001 to 2017 on the topic: the metaphysics of science. I have not discovered one work that mentions or refers to AOE in any way whatsoever - let alone uses AOE to make a fruitful contribution to the metaphysics of science.

At once a dreadful possibility must be confronted. It could be that arguments in support of AOE are so embarrassingly bad that it is entirely understandable, and entirely justifiable, that the body of subsequent work on the metaphysics of science makes no mention of what I have done on the topic.

However, those who have taken the trouble to read work on AOE have on the whole praised it and endorsed what I have to say. ${ }^{22}$ Thus George Kneller declared "Maxwell's theory of aim-oriented empiricism is the outstanding work on scientific change since Lakatos, and his thesis is surely correct... Of the theories of scientific change and rationality that I know, Maxwell's is my first choice. It is broad in scope, closely and powerfully argued" (Kneller, 1978, pp. 84 and 91). J.J.C. Smart commented "Maxwell's aim oriented empiricism [is] intelligible and persuasive ... the main ideas are important and appealing ... an important contribution to the philosophy of physics" (Smart, 2000). F.A. Muller remarked that "[Maxwell's] insights are of everlasting importance to the philosophy of science, the fact that he stands on the shoulders of giants (Hume, Popper) notwithstanding" (Muller, 2004). More recently, Alasdair MacIntyre wrote "in his The Comprehensibility of the Universe, Maxwell treats the intelligibility and unity of the physical universe as something to which our commitment is inescapable, once we have understood the theoretical aims of physical enquiry (see especially pp. 180-181)" (MacIntyre, 2009). And others referred to in note 23 make similar comments.

But even if my argument for aim-oriented empiricism (AOE) is not hopelessly invalid, it could still fail to establish the 16 points listed above. After all, most of what philosophers have claimed down the centuries has turned out to be wrong, or at least unsubstantiated, so it is reasonable to suppose that the same might go for what I claim to have established as well. I am of the view that the case for AOE is unanswerable, but I am the author, so I might be expected to adopt that attitude in any case.

The argument of this paper does not require, however, that I have decisively established AOE. All that it requires is that a good case has been made out for AOE, one that has sufficient merit to deserve discussion. That is all that is required to make it almost inexplicable that at least 53 subsequent works on the metaphysics of science ignore entirely the case for AOE.

Of the 53 works on the metaphysics of science that I have examined, published between 2000 and 2017, just one refers to my earlier work in the field, indicated above, and that work shows no sign of having grasped the significance of the argument for AOE. One other author knows of, and approves of, my work, but again makes no reference to it in the publications under consideration. ${ }^{23}$ The remaining 51 authors writing on the metaphysics of science seem entirely oblivious of AOE - somewhat to their cost. I now discuss eleven representative samples from these 53 works on the metaphysics of science. ${ }^{24}$

In The Metaphysics of Science, Craig Dilworth puts forward the view that science is made up of three ingredients: metaphysical principles, theories and empirical laws (Dilworth 2007). 
Unlike all the other works under consideration, Dilworth does refer to my earlier work; in four footnotes, he quotes approvingly from Maxwell (1984), three of these quotations actually encapsulating aspects of the view of science in question. And yet, not only does Dilworth fail to acknowledge his debt to my earlier work; he fails to exploit elements of this work which would have considerably improved his book. Most notably, Dilworth fails to exploit the key argument for AOE, sketched above in section 2 concerning the fact that physics only ever accepts unified theories. As a result of this failure, Dilworth does not really have an argument in support of the three ingredient view of science he expounds.

Furthermore, Dilworth's metaphysical principles fail to assert that underlying unity is the key metaphysical presupposition of physics. Dilworth does recognize that the metaphysical principles of science need to be criticized and modified as science proceeds, but he does not use the hierarchical structure of AOE, so essential for the progressive improvement of problematic metaphysical presuppositions of physics. Dilworth's three ingredient view of science is supposed to apply, unchanged in basic structure, to all the diverse sciences, even to economics, whereas AOE reveals that presuppositions and methods differ substantially, as one goes from one science to another. For a much more detailed critical appraisal of Dilworth's book see Maxwell (7009c).

Ross, Ladyman, and Spurrett (chapter one of Ladyman et al, 2007) does an excellent job in decisively criticizing that enterprise of analytic philosophy that seeks to do metaphysics independently of, or in ignorance of, modern physics. It is clearly recognized that the task of scientific metaphysics is to provide a basis for the unification of two or more accepted fundamental theories of physics, all such proposals being conjectural, and likely to be false. The account of unification is however unsatisfactory - it takes Kitcher $(1976,1981)$ for granted. ${ }^{25}$ There is no hint of the conception of unification that is required, indicated briefly above: see Maxwell (1998, chs. 3-4; 2004a, 160-174). Much more seriously, there is no hint of the key argument of section 2 above for AOE. Far from explicating something like the hierarchical meta-methodology of AOE, designed to subject the metaphysics of physics to sustained critical scrutiny and attempted improvement, it is actually stated at one point that "there is no such thing as "scientific method"' (p. 27). Like Dilworth, Ross et al. does not put the metaphysics of physics into anything remotely like the required framework of AOE.

Bishop (2003) sets out to defend arguments for anti-realism based on the pessimistic induction against scientific realists who employ some particular theory of reference. Granted AOE (which Bishop of course ignores), the so-called "pessimistic induction" is not pessimistic at all. The manner in which theoretical physics has advanced since Newton, from one false theory to another, each enhancing unity, and predicting a wider range of phenomena more accurately than its predecessor, is exactly the way physics should advance if it is making progress - granted AOE and physicalism (as AOE characterizes physicalism). This leap from pessimism to optimism does not, however, get rid of the problem for scientific realism - except that it becomes possible for the realist to hold that the most secure realist conjectures are to be found at the level of metaphysics (level 4 of the diagram) rather than at the level of physical theory. Bishop is surely correct to argue that realists should not respond to the anti-realist by means of a theory of reference cooked up to establish that terms of false theories do, after all, refer - the "flight-to-reference" as Bishop calls it. A quite different strategy is, however, available to the realist. The issue, it may be argued, has nothing to do with reference at all; it has to do with what is being conjectured to exist, how precisely or imprecisely specified. "Electrons exist" may be interpreted in such a way that what is being asserted to exist, here, only exists if the relevant theory of electrons that is being presupposed is true (the standard model perhaps). At the other extreme, electrons may be characterized in a much looser way as an entity that has a mass and negative electric charge between such and such values, mass and charge being characterized in a loose way as well, with minimum 
theoretical content. Electrons in the first sense only exist if the relevant physical theory is true; AOE tells us that they do not exist (even if the relevant theory has not been refuted - as the standard model has not). Electrons in the second sense do not require the full theory to be true to exist; they require physical statements to be true that have far, far less content statements which thus stand a far better chance of truth. ${ }^{26}$

Chakravartty (2007) seeks to articulate a version of scientific realism that does justice both to modern science and to the critics of realism, but all within the framework of standard empiricism, which is taken for granted throughout. Problems posed by inference to the best explanation, the underdeterminations of theory by evidence, and the pessimistic induction are all clearly discussed, but there is no discussion of the aim-oriented empiricist solutions to these problems that has been put forward and argued for earlier. ${ }^{27}$ The key argument for AOE of section 2 above does not appear, and there is no hint of the need for a new hierarchical meta-methodology for physics designed to facilitate the improvement of the metaphysics of physics as science proceeds.

Chakravartty (2017) is as admirably lucid as its predecessor of a decade earlier. It seeks to do justice to both scientific and philosophical approaches to ontology. Both are needed. The nearest the book comes to $\mathrm{AOE}$ is in stressing that metaphysical inferences are inferences to the best explanation, there being in this an a priori element. A priori metaphysical presuppositions of science are discussed (ch. 3), but the key argument of section 2 above makes no appearance; AOE and its implications are ignored. ${ }^{28}$

Lange (2009) is concerned to make sense of the distinction between laws and true accidental generalizations. His proposed solution is that laws just have the remarkable property of remaining true in all counterfactual possibilities consistent with their all being true. Lange goes on to argue that this proposal, elaborated somewhat, gives to laws a kind of "natural necessity".

Even if Lange's intricate proposal succeeds in distinguishing laws from accidental facts, it does not succeed in accounting for the necessity of laws in the full-blooded sense of logical or analytic necessity. Lange seems to be oblivious to the fact that this problem was solved in a paper published over four decades earlier: see Maxwell (1968a). In that paper I argued that laws can be regarded as explicating what it means to attribute necessitating properties to physical entities. Newton's theory of gravitation can be interpreted as attributing the necessitating property of gravitational charge, $g$, to objects, with $\mathrm{g}=\mathrm{m}$, where $\mathrm{m}$ is mass. Two objects possessing Newtonian gravitational charge $\mathrm{g}_{1}$ and $\mathrm{g}_{2}$ of necessity attract each other with a force $\mathrm{F}$ which is such that $\mathrm{F}=\mathrm{Gg}_{1} \mathrm{~g}_{2} / \mathrm{d}^{2}$. Newton's law of gravitation merely explicates what it means to assert that an object has Newtonian gravitational charge $\mathrm{g}$. Newton's law is true analytically; it is an analytically necessary truth. Is that not fatal to this view? No. The empirical content of Newton's theory is contained in an existential assertion along the lines of: the world is made up of objects that possess the necessitating property of gravitational charge (equal to their mass). In a sense, laws are not refuted. Associated existential assertions are refuted, and the law becomes redundant: nothing exists to which it is applicable. Despite Hume, it is possible that there are (analytically) necessary connections between successive states of affairs, and we should interpret physics as seeking to discover what they are. ${ }^{29}$

A law, then, is a law because there exist objects that possess necessitating properties corresponding to the law (as gravitational charge corresponds to Newton's law, essentialistically interpreted). No such necessitating property exists that corresponds to a true accidental generalization.

Maudlin (2007) makes clear the excellence, and the limitation, of the book in its introduction. It is announced that "metaphysics, in so far as it is concerned with the natural world, can do no better than to reflect on physics. Physical theories provide us with the best 
handle we have on what there is, and the philosopher's proper task is the interpretation and elucidation of those theories" (p. 1). What Tim Maudlin neglects, however, is the key argument of section 2 above, which bring into focus a number of metaphysical theses about the nature of the universe, inherent in the methods of physics, and thus presupposed by and fundamental to physics, which the book entirely ignores. ${ }^{30}$

Morganti (2013) seeks to clarify the relationship between physics and metaphysics in such a way that justice is done both to the idea that science is fundamental for the development of philosophical ideas, and that philosophy has something substantial to contribute itself. Specific topic discussed include individuality in quantum theory, space and time, and the part/whole relationship. Nowhere is there a hint of the key argument of section 2 above; a consideration of this argument, and of AOE that follows from it, would have transformed the book.

In their excellent introduction, Mumford and Tugby (2013) begin by stating that "Science can only exist in an ordered, patterned world, and it is argued that the core aim of the metaphysics of science is to investigate the nature of that order" (p.3). This promising beginning does not, however, lead on to the point that this metaphysical thesis of patterned order is a problematic presupposition of physics, very likely to be false in the specific form adopted at any given stage in the development of physics, a new hierarchical methodology for physics being required to subject the thesis to sustained criticism and attempted improvement.

Ross et al (2013) is a collection of essays devoted to the idea that metaphysics must be based on modern science. The book contains contributions from Harold Kincaid, Anjan Chakravartty, Paul Humphreys, Andrew Melnyk, Daniel Dennett, James Ladyman and Don Ross, Mark Wilson, Michael Friedman and Jenann Ismael. As Kincaid mentions in his introduction, many of these contributors have recently published books on scientific metaphysics. It is thus highly significant that nowhere do we find, in this collection, any mention of "the basic argument" that leads one to acknowledge that physics makes a highly problematic metaphysical presupposition concerning underlying unity in nature, a new metamethodology being required to subject this presupposition to sustained scrutiny, and attempted improvement. The first steps towards AOE are not considered, let alone taken.

Trout (2016) argues that the birth of modern science had nothing to do with the adoption of scientific method. It was a matter of sheer chance. Newton, by sheer good luck, hit upon a scientifically fruitful metaphysics. AOE, which incorporates metaphysics into scientific method, is entirely ignored. For detailed criticism of Trout (2016) see Maxwell (2017d).

What all these authors ignore is a central source for the metaphysics of physics that comes, not from physical theory, but from the methods of physics - specifically that methodological rule that asserts: in order to be acceptable, a fundamental physical theory must be (sufficiently) unified. ${ }^{31}$ It is the persistent acceptance of unified theories only, when endlessly many empirically more successful disunified rivals are available, that commits physics to the metaphysical presupposition that, at the very least, the universe is such that all disunified theories are false. Recognition of this point constitutes the key step towards adopting the hierarchical methodology of AOE. ${ }^{32}$

\section{Broader Implications}

The argument for AOE, sketched in sections 1 and 2 above, is the first step of a broader argument about academic inquiry as a whole. For over 40 years I have argued that academic inquiry as it exists at present, devoted in the first instance to the pursuit of knowledge, is damagingly irrational in a structural way when judged from the standpoint of helping to promote human welfare. We need a new, more rigorous kind of academic enterprise devoted to helping humanity resolve problems of living, including global problems, by intellectual, 
educational and technological means. The basic intellectual aim needs to be wisdom, progress towards a wiser world, and not just the acquisition of specialized knowledge. ${ }^{33}$ Here wisdom is to be understood to be the capacity and the active endeavour to realize what is of value in life for oneself and others, wisdom in this sense including knowledge, technological know-how and understanding, but much else besides.

What role does the argument for AOE have in this broader argument for the need to transform academia as a whole? The answer takes us back to the 18th century French Enlightenment. The basic idea of the Enlightenment, I argue, was to learn from scientific progress how to achieve social progress towards an enlightened world. In order to develop this idea properly, three steps need to be got right. First, the progress-achieving methods of science need to be correctly identified. Second, these methods need to be generalized correctly, so that they become fruitfully applicable to all worthwhile endeavours with problematic aims, and not just to science. Third, these generalized progress-achieving methods need to be got into social life, into all enterprises and institutions with problematic aims besides science: politics, industry, agriculture, the media, the law, education, international relations and, above all, the endeavour to make progress towards a good, enlightened world (in so far as such an endeavour exists).

Unfortunately, the philosophes in the 18th century got all three steps wrong. The botched version of the profound Enlightenment idea that resulted was developed throughout the 19th century, and built into academia around the world in the early 20th century. Universities still suffer from these ancient blunders today. It is this that renders academic inquiry damagingly irrational in a wholesale, structural fashion, and makes it such an urgent matter that these structural defects be put right.

The philosophes' worst mistake was at step three. They took it to be to develop social science alongside natural science (a mistake we still have built into academia today). But correctly implemented, this third step involves getting progress-achieving methods, generalized from those of natural science, not into social science, but directly into social life itself, into all our other social and institutional endeavours besides science, so that we may make progress towards a wiser, more enlightened world. Social inquiry needs to be developed as social methodology and not, primarily, as social science. The primary task of academia, implementing step three properly, is to help humanity resolve conflicts and problems of living in increasingly cooperatively rational ways by exploiting methods generalized from those of science. Intelligent public education about what our problems are, and what we need to do about them, becomes a basic task of the university. ${ }^{34}$

However, vital as it is to get step three right, it is also important to get step one right as well. Here, the philosophes made the blunder of taking versions of standard empiricism for granted, just as scientists and philosophers of science do today. The all-important point to appreciate is that, in life, our personal, social, institutional, even global aims are often profoundly problematic. They are unrealizable or, if realizable, burdened with all sorts of unforeseen, undesirable consequences. Methods arrived at by generalizing those of standard empiricism cannot help, but the aim-improving meta-methodology of AOE, when generalized, is, potentially, by contrast, profoundly helpful. Just as in physics AOE helps improve the aims of physics, so too in life, the generalized version of AOE - namely aimoriented rationality, is potentially profoundly helpful in enabling us to improve problematic personal, social and institutional aims, as we live.

In this way, the argument for AOE plays a crucial role in the argument for the urgent need to transform academia so that the basic aim becomes to help humanity resolve our grave global problems and make progress towards a more enlightened world.

Not for one moment am I arguing that AOE deserves to be accepted because of the key role it plays in this broader argument. Of course not! AOE, and the argument in support of 
it, must be assessed independently of any use to which they may be put. I do think however that the fact that AOE is a part of a broader argument concerning the rationality and human value of academic inquiry, and our capacity to solve the grave global problems that confront us, provides grounds for giving the doctrine some critical attention.

What, then, needs to be said about the significance of AOE? First, the view is significant in its own right. AOE has important implications, not just for the metaphysics of science, not just for philosophy, but for the whole way in which we understand, do, and teach science. It cries out for the critical attention of philosophers of science. ${ }^{35}$ It should not be condemned to the neglect it has received so far, just because of this long-standing neglect, or because of the fact that it differs, in some important respects, from views current in the discipline. Second, AOE is significant because of the key role it plays in the broader argument for a revolution in academia so that it may become rationally organized and devoted to helping humanity solve global problems and make progress towards a wiser world.

\section{What Accounts for the Long-Standing Neglect of Aim-Oriented Empiricism?}

Why has AOE been so resoundingly ignored in all subsequent work on the metaphysics of science, from 2007 to 2017? The reason, I suggest, is that, in moving from standard to aimoriented empiricism, a revolution is required in science, in the philosophy of science, and in the relationship between the two. This revolution involves a dramatic change of paradigm, for science and for the philosophy of science. Thomas Kuhn reminds us graphically how fiercely paradigm changes can be resisted (Kuhn, 1970, 150-159). The first, very effective step in this resistance is to ignore the arguments or the evidence for the new paradigm. ${ }^{36}$

But why, it may be asked, should philosophers of science want to ignore AOE when it has such fruitful implications for the subject? Moving from standard to aim-oriented empiricism involves transforming much of the character of philosophy of science - certainly that part of it devoted to the metaphysics of science. If AOE were to be adopted, work pursued in accordance with standard empiricism would abruptly become passé if not irrelevant. Expertise built up over decades might become abruptly outdated. Philosophy of science pursued within the new paradigm of aim-oriented empiricism sets new tasks, new problems, to be tackled, while old tasks and problems fall by the wayside. ${ }^{37}$ Established reputations in the field may turn out not to be so well-established after all. Careers may suffer set-backs. Long established routines of thought, research and teaching all need to be changed. Few individuals want to risk their career by taking up such an activity-transforming view, and so few individuals do.

In addition, a philosopher of science accustomed to think of science in terms of some version of standard empiricism, may find $\mathrm{AOE}$ quite blatantly untenable, on first encountering the view. Philosophers of science know that attempts to solve the problem of induction by means of an appeal to the uniformity of nature, or to some such metaphysical thesis, are all doomed to fail. But does not AOE do just that? As Bas van Fraassen has put it "From Gravesande's axiom of the uniformity of nature in 1717 to Russell's postulates of human knowledge in 1948, this has been a mug's game" (van Fraassen 1985, pp. 259-60). AOE does not deserve consideration because it is a "mug's game".

Why is it deemed to be such a "mug's game" to appeal to some metaphysical thesis of uniformity? First, because it seems quite impossible to provide evidence or argument in support of the truth of such a thesis. And secondly, the attempt to solve the problem of induction by means of some such appeal seems to be viciously circular, and so invalid. It is not appreciated that both objections are decisively demolished in my work. The basic argument for AOE is that some kind of metaphysical thesis of unity is inevitably implicit in the manner physics persistently only accepts unified theories, even though endlessly many empirically more successful disunified rivals are always available. Precisely because this 
metaphysical thesis is a pure conjecture about the ultimate nature of the universe (just that about which we are most ignorant) - the specific version of the thesis that physics implicitly accepts at any stage in its development being almost certainly false - it is all-important that this conjecture be made explicit, so that it can be critically assessed and, we may hope, improved. The irredeemably conjectural character of the presupposed metaphysical thesis, plus its influence over what physical theories are both sought and accepted, is precisely what makes it so important that it be made explicit so that it can be explicitly scrutinized and, we may hope, improved. It needs to be made explicit in the interests of intellectual rigour, and in the interests of progress in physics. Not to do so is the "mug's game". ${ }^{38}$

As for the charge of vicious circularity, it is indeed true that AOE proudly proclaims that its hierarchical structure facilitates the improvement of metaphysical theses, and associated methods, in the light of improvement of accepted physical theory, and improvement of physical theory in the light of improvement of metaphysical theses, and associated methods. There is, in other words, something like positive feedback between improving scientific knowledge, and improving aims and methods of science - improving knowledge about how to improve knowledge. How can such an ostensibly viciously circular procedure conceivably be rigorous? The answer is that whether or not such a procedure, if implemented properly, can meet with success depends crucially on what kind of universe we are in. In some possible universes, such a procedure would indeed lead to disaster. But other possible universes are such that this positive-feedback procedure, if carried out properly, will not lead to disaster, and may lead to real success. Meta-knowability, the thesis at level 6 in the figure of AOE, asserts that this universe is such that the positive-feedback procedure, if carried out properly, will not lead to disaster. And furthermore, crucially, the argument for accepting meta-knowability as an item of scientific knowledge makes no appeal whatsoever to the success of science. In this way AOE renders its positive-feedback procedure legitimate and intellectually rigorous. ${ }^{39}$ It deserves to be noted that this positive-feedback procedure is actually employed in science, at both the theoretical, and the experimental levels. New theories lead to new symmetry principles which, in turn, lead to new theories. New scientific knowledge leads to new instruments which in turn lead to new knowledge. ${ }^{40}$

Scientists have particularly strong (invalid) reasons for rejecting AOE. To begin with, science students are not taught standard empiricism; it is rather implicit in much that they are taught, and is thus acquired as an unquestioned, implicit dogma, held beyond question. One consequence is that scientists unthinkingly take it for granted that science is to be distinguished sharply from other fields of endeavour, such as politics and religion, in that these other fields appeal to articles of faith upheld independently of, even in contradiction with, the facts of observation and experiment. In science, so it is maintained, this does not happen. In science, everything is accepted and rejected on the basis of evidence. This is, of course, the standard empiricist view. But AOE requires one to reject it. Science does have an article of faith - or rather a whole hierarchy of such articles. No longer is the simpleminded standard empiricist distinction between science and religion possible. A revised distinction is, however, available. In science, articles of faith are subjected to sustained critical scrutiny, those versions of the article of faith being accepted provisionally which seem best to help promote the growth of scientific knowledge. In all too many religions, articles of faith are not treated in this conjectural, critical, rational fashion.

Such a distinction can only be drawn, however, if science does accept and implement AOE. At present, given that the scientific community takes standard empiricism for granted, it cannot be drawn in this way. Scientists deny that there are any articles of faith in science, upheld on grounds independent of evidence. The result is that these metaphysical articles of faith are adopted in a thoroughly unacknowledged, and thus dogmatic, fashion. (What is unacknowledged cannot be criticized.) Science is as a result rather closer to irrational 
religion that it might like to acknowledge. All this makes it difficult for the scientific community to abandon standard empiricism, and adopt and implement AOE instead.

\section{References}

Agassi, J., 2008, Review, Philosophy of Science, 75, 4, 477-479.

Armstrong, D., 1978, A Theory of Universals, Cambridge University Press, Cambridge. , 1983, What is a Law of Nature?, Cambridge University Press, Cambridge.

Bird, A. 2007, Nature's Metaphysics: Laws and Properties, Clarendon, Oxford.

Bishop, M. (2003). The pessimistic induction, the flight to reference and the metaphysical zoo. International Studies in Philosophy of Science 17: 161-78

Bittner, T., 2004, Review, Philosophical Books 45, 182.

Campbell, J.K., M. O'Rourke and M.H. Slater, eds., 2011, Carving Nature at its Joints: Natural Kinds in Metaphysics and Science, MIT Press, Cambridge, Mass.

Chakravartty, A., 1999, Times Higher Education Supplement, 24 September, p. 24. 2007, A Metaphysics for Scientific Realism. Cambridge University Press,

Cambridge. 2017, Scientific ontology : integrating naturalized metaphysics and voluntarist epistemology, Oxford University Press, Oxford.

Collingridge, D., 1985, Reforming Science, Social Studies of Science, 15, 763-9.

Davidow, J., 2006, Review, Learning for Democracy, 2, 78-80.

Dilworth, C, 2007, The Metaphysics of Science: An Account of Modern Science in Terms of Principles, Laws and Theories, Springer, Dordrecht.

Easlea, B., 1986, Review, Journal of Applied Philosophy 3, 139-40.

Ellis, B. 2001: Scientific Essentialism. Cambridge: Cambridge University Press.

Grebowicz, M., 2006, Review, Metascience, 15, 141-144.

Harris, M. 1980, Cultural Materialism, Vintage, London, 25-6.

Hendry, J., 1989, Review, British Journal for the History of Science, 22, 246-7.

Iredale, M., 2005, The Philosopher's Magazine, 31, 2005, 86-87.

Juhl, C.F., 2000, Review, International Philosophical Quarterly, XL, 4, 517-8.

Kneller, G. 1978. Science as a Human Endeavor, New York: Columbia University Press.

Koertge, N., 1989, Review, Isis, 80, 1, 146-7.

Kuhn, T.S., 1970, The Structure of Scientific Revolutions, University of Chicago Press, Chicago.

Ladyman, J., D. Ross and D. Spurrett with J. Collier, 2007, Every Thing Must Go: Metaphysics Naturalized, Oxford University Press, Oxford.

Lange, M. 2009. Laws and Lawmakers: Science, Metaphysics and the Laws of Nature. Oxford: Oxford University Press.

Longuet-Higgins, C. 1984. For goodness sake. Nature, 312, 204.

Lorimer, D., 2017, Aim-Oriented Empiricism, Paradigm Explorer, 2017/2, 43-44.

Lowe, E.J., 2006, The Four-Category Ontology: A Metaphysical Foundation for Natural Science, Oxford University Press, Oxford.

MacIntyre, A. 2009. The Very Idea of a University. British Journal of Educational Studies 57, 4, p. 358.

Maudlin, T. 2007: The Metaphysics within Physics. Oxford: Oxford University Press.

Maxwell, N., 1966, Physics and Common Sense, British Journal for the Philosophy of Science, 16, 295-311. 1968a, Can there be Necessary Connections between Successive Events?, British

Journal for the Philosophy of Science, 19, 1-25. 1968b, Understanding Sensations, Australasian Journal of Philosophy, 46, 127-146. 

$131-52$

1972a, A Critique of Popper's Views on Scientific Method, Philosophy of Science 39, 1972b, A New Look at the Quantum Mechanical Problem of Measurement, American Journal of Physics 40, 1431-1435.

1973, The Problem of Measurement - Real or Imaginary?, American Journal of

Physics, vol. 41, 1022-1025.

1974, The Rationality of Scientific Discovery, Philosophy of Science, 41, 123-153.

1976a, What's Wrong With Science?, Bran's Head Books, Hayes, Middlesex.

1976b, Towards a Micro Realistic Version of Quantum Mechanics, Parts I and

II, Foundations of Physics 6, 275-92 and 661-76.

1980, Science, Reason, Knowledge and Wisdom: A Critique of Specialism, Inquiry, vol. 23, 19-81.

1982, Instead of Particles and Fields, Foundations of Physics, vol. 12, 607-631.

1984, From Knowledge to Wisdom: A Revolution in the Aims and Methods of

Science, Blackwell, Oxford.

1988, Quantum Propensiton Theory: A Testable Resolution of the

Wave/Particle Dilemma, British Journal for the Philosophy of Science 39, 1-50. 1992, What Kind of Inquiry Can Best Help Us Create a Good World?, Science,

Technology and Human Values, vol. 17, 205-27.

1993a, Induction and Scientific Realism, Parts I, II and III, British Journal for the

Philosophy of Science, vol. 44, 61-79, 81-101, and 275-305.

1993b, Beyond Fapp: Three Approaches to Improving Orthodox Quantum

Theory and An Experimental Test, in Bell's Theorem and the Foundations of Modern

Physics, edited by A. van der Merwe, F. Selleri and G. Tarozzi, World Scientific,

362-370.

1993c, Does Orthodox Quantum Theory Undermine, or Support, Scientific Realism?,

The Philosophical Quarterly 43, 139-57.

1994, Particle Creation as the Quantum Condition for Probabilistic Events to

Occur, Physics Letters A 187, 351-5.

1998, The Comprehensibility of the Universe: A New Conception of Science,

Clarendon Press, Oxford.

2000a, Can Humanity Learn to become Civilized? The Crisis of Science without

Civilization, Journal of Applied Philosophy, vol. 17, 29-44.

2001, The Human World in the Physical Universe: Consciousness, Free Will and

Evolution, Rowman and Littlefield, Lanham, Maryland.

2004a, Is Science Neurotic?, Imperial College Press, London.

2004b, Does Probabilism Solve the Great Quantum Mystery?, Theoria vol.

19/3, no. 51, 321-336.

2005, Popper, Kuhn, Lakatos and Aim-Oriented Empiricism, Philosophia, vol. 32,

nos. 1-4, 181-239.

, 2006, Practical Certainty and Cosmological Conjectures, in Is there Certain

Knowledge?, ed. Michael Rahnfeld, Leipziger Universitätsverlag, Leibzig, 44-59.

2007a, From Knowledge to Wisdom: A Revolution for Science and the Humanities,

Pentire Press, London (2nd revised and extended edition).

2007b From Knowledge to Wisdom: The Need for an Academic Revolution, London

Review of Education, vol. 5, no. 2, 97-115.

2008, Are Philosophers Responsible for Global Warming?, Philosophy Now, issue

$65,12-13$. 
2009a, How Can Life of Value Best Flourish in the Real World?, in Science and the Pursuit of Wisdom: Studies in the Philosophy of Nicholas Maxwell, ed. L. McHenry, Ontos Verlag, Frankfurt, 1-56.

2009b, Review, International Studies in the Philosophy of Science, 23 (2) 228 - 232. 2010, Reply to Comments on Science and the Pursuit of Wisdom, Philosophia, vol. 38, no. 4, 667-690.

2011a, A Priori Conjectural Knowledge in Physics, in What Place for the A Priori?, ed. M. Shaffer and M. Veber, Open Court, Chicago, 211-240.

2011b, Is the Quantum World Composed of Propensitons?, in Probabilities, Causes and Propensities in Physics, ed. M. Suárez, Synthese Library, Springer, Dordrecht, 221243.

2012, Arguing for Wisdom in the University: An Intellectual Autobiography,

Philosophia, vol. 40, no. 4, 663-704, reprinted in Maxwell (2014b, ch. 5).

2013a, Has Science Established that the Cosmos is Physically Comprehensible?, in

Recent Advances in Cosmology, Travena, A and Soen, B., eds, Nova Publishers Inc, New

York, Chapter One, 1-56. $17-18$.

2013b, Knowledge or Wisdom?, The Philosophers' Magazine, issue 62, 3rd quarter

2014a, How Universities Can Help Create a Wiser World: The Urgent Need for an Academic Revolution, Imprint Academic, Exeter.

2014b, Global Philosophy, Imprint Academic, Exeter.

2014d, Unification and Revolution: A Paradigm for Paradigms, Journal for General

Philosophy of Science, 45, 1, 133-149.

2015, What's Wrong With Aim-Oriented Empiricism?, Acta Baltica Historiae et

Philosophiae Scientiarum, vol. 3, no. 2, 5-31.

2016a, Can Scientific Method Help Us Create a Wiser World?, in N. Dalal, A.

Intezari and M. Heitz, ed., Practical Wisdom in the Age of Technology: Insights, Issues

and Questions for a New Millennium, Ashgate, Farnham.

2016b, Popper's Paradoxical Pursuit of Natural Philosophy, in J. Shearmur and G.

Stokes, eds., The Cambridge Companion to Popper, Cambridge University Press,

Cambridge, ch. 7, 170-207.

2017a, Understanding Scientific Progress, Paragon House, Saint Paul, Minnesota.

2017b, In Praise of Natural Philosophy, McGill-Queen's University Press, Montreal.

2017c, Karl Popper, Science and Enlightenment, UCL Press, London.

2017d, Review of J.D. Trout's Wondrous Truths, Acta Baltica Historiae et

Philosophiae Scientiarum, 5, 2, 108-115.

2019a, The Metaphysics of Science and Aim-Oriented Empiricism, Springer, Cham.

2019b, A New Task for Philosophy of Science, Metaphilosophy, 50.

Cham.

2019c, Science and Enlightenment: Two Great Problems of Learning, Springer,

McHenry, L. 2000. Review. Mind, 109, 162-6.

, ed., 2009, Science and the Pursuit of Wisdom: Studies in the Philosophy of Nicholas

Maxwell, Ontos Verlag, Frankfurt.

McNiven, C., 2005, Review, Journal of Consciousness Studies, 12, 3, 88-9.

Midgley, M., 1986, University Quarterly: Culture, Education and Society, 40, 4, 425-7.

Morganti, M., 2013, Combining Science and Metaphysics, Palgrave Macmillan, London.

Muller, F.A. 2004. Maxwell's Lonely War. Studies in History and Philosophy of Modern

Physics, 35, 109-110 \& 117.

2008, In Defence of Constructive Empiricism: Maxwell's Master

Argument and Aberrant Theories. Journal of General Philosophy of Science, 39, pp. 
131-156.

Mumford, S. and M. Tugby, eds., 2013, Metaphysics and Science, Oxford University Press, Oxford.

Müürsepp, P., 2014, Review, Dialogue and Universalism, 2, 247. , 2017, Review, Review of Metaphysics, 71, 2, 387-388.

Pandit, G. L., 2010, How Simple is it for Science to Acquire Wisdom According to its Choicest Aims?, Philosophia, 38, 4, 649-666.

Perovic, S., 2007, Review, British Journal for the Philosophy of Science, 58, 361-3.

Ravetz, J., 1987, Review, British Journal for the Philosophy of Science, 38, 265-8.

Rescher, N., 2000, Nature and Understanding: The Metaphysics and Methods of Science, Oxford University Press, Oxford.

Richards, S., 1985, Philosophical Aspects of Science, Annals of Science, 42, 148-9.

Ross, D., J. Ladyman and H. Kincaid, eds., 2013, Scientific Metaphysics, Oxford University Press, Oxford.

Roush, S., 2001, Review, The Philosophical Review 110, 85-7.

Shanks, N., 2000, Review, Metascience 9, 294-8.

Slater, M. and S. Yudell, eds., 2017, Metaphysics and the Philosophy of Science, Oxford University Press, Oxford.

Smart, J.J.C. 2000. Review. British Journal for the Philosophy of Science. 51, 907-11.

Tooley, M., 1977, The Nature of Law, Canadian Journal of Philosophy 7, 667-698.

Trout, J.D., 2016, Wondrous Truths, Oxford University Press, Oxford.

van Fraassen, B. C. (1985). Empiricism in the philosophy of science. In P. M. Churchland \& C. A. Hooker (Eds.), Images of science (pp. 245-308). Chicago: University of Chicago Press.

Vicente, A., 2010, An Enlightened Revolt: on the Philosophy of Nicholas Maxwell, Philosophia 38, 4, 631-648.

\section{Notes}

${ }^{1}$ See Maxwell (1974). This publication grew out of Maxwell (1972a). Both were associated with earlier work on the metaphysics of science: see Maxwell $(1966 ; 1968 \mathrm{a} ; 1968 \mathrm{~b})$.

${ }^{2}$ See Maxwell (1980; 1984, chs. 5 and 9; 1993a; 1998; 2001; 2004a; 2005; 2006).

${ }^{3}$ In order to be unified, the content of a physical theory, what it asserts about the world, must be the same everywhere, throughout all the phenomena to which the theory applies. If, in moving throughout the space of possible phenomena to which a theory applies, the theory is such that in $\mathrm{N}$ distinct regions of the space, the content of the theory in any region is the same throughout, but different from all the other regions, then the theory is disunified to degree $\mathrm{N}$. For unity we require $N=1$. See Maxwell (1998, chs. 3 and 4; 2004a, pp. 160-174). For a recent exposition see Maxwell (2017a, ch. 5 and appendix 1).

${ }^{4}$ The $17^{\text {th }}$ century corpuscular hypothesis is, perhaps, an exception. It is refuted, perhaps, by the observation that there appear to be attractive and cohesive forces in the world.

${ }^{5}$ Maxwell (1974; 1984, chs. 5 and 9; 1998; 2004a; 2012; 2014a; 2017a; 2017b).

${ }^{6}$ Maxwell (1998, ch. 2; 2017a).

${ }^{7}$ Maxwell (1984, pp. 231-2, 235 and 240-42; 2004a, pp. 34-51).

${ }^{8}$ Maxwell (1998, especially pp. 19-20, 26, 98 and ch. 5; 2017a, ch. 9).

${ }^{9}$ See note 9 .

${ }^{10}$ Maxwell (1974; 1993a, pp. 275-305; 1998, pp. 29-30; 2004a, pp. 42-7; 2017a, ch. 10).

${ }^{11}$ Maxwell (1976b, pp. 276-8; 1988, pp. 2-3; 1998, pp. 231-2). 
${ }^{12}$ For Maxwell's own efforts at developing a fully micro-realistic, fundamentally probabilistic version of quantum theory, empirically testable, and free of the defects of orthodox quantum theory, see Maxwell (1972b; 1973; 1976b; 1982; 1988; 1993b; 1994; 2004b; 2011b).

${ }^{13}$ Maxwell (1998, pp. 211-2; 2017a, pp. 83-6).

${ }^{14}$ For a lucid exposition of this point see Maxwell (2017a, pp. 74-82), See also Maxwell (2017b, ch. 5).

${ }^{15}$ For Maxwell's early attempts at solving the problem of induction see Maxwell (1974; 1984, pp. 218-230; 1998, ch. 5). For progressively improved expositions of the solution provided by AOE, see Maxwell (2007a, pp. 400-430; 2017a, ch. 9).

${ }^{16}$ Maxwell (1998, chs. 3 and 4; 2004a, pp. 160-174; 2007a, pp. 373-86; 2017a, ch. 5 and appendix 1).

${ }^{17}$ See note 16.

${ }^{18}$ Maxwell (1998, pp. 211-7; 2007a, pp. 395-400 and 430-432; 2017a, ch. 8).

${ }^{19}$ Maxwell (1974; 1984, pp. 235-242; 1993a, pp. 275-305; 1998, pp. 219-223). See especially Maxwell (2017b, ch. 5).

${ }^{20}$ Maxwell (2005; 2014d).

${ }^{21}$ Maxwell (1993a, pp. 81-101; 1993c).

${ }^{22}$ See Kneller (1978, 80-7 and 90-1); Harris (1980); Longuet-Higgins (1984); Collingridge (1985); Richards (1985); Midgley (1986); Easlea (1986); Ravetz (1987): Hendry (1989); Koertge (1989); Chakravartty (1999); Smart (2000); Juhl (2000); McHenry (2000); Shanks (2000); Roush (2001); Bittner (2004); Muller (2004); Iredale (2005); McNiven (2005); Davidow (2006); Grebowicz (2006); Perovic (2007); Agassi (2008); MacIntyre (2009); Müürsepp (2014; 2017) and Lorimer (2017).

${ }^{23}$ Anjan Chakravartty wrote a favourable review of Maxwell (1998): see Chakravartty (1999). Maxwell's work is however ignored in Chakravartty (2007; 2017).

${ }^{24}$ The 53 works in question, listed roughly in the order in which they were consulted, are Dilworth (2007); D. Ross, J. Ladyman, D. Spurrett and J. Collier in Ladyman et al. (2007); Bishop (2003); Chakravartty (2007; 2017); Lange (2009); Ellis (2001); Bird (2007); Maudlin(2007); Morganti (2013); S. Mumford, M. Tugby, J.T. Roberts, J. Woodward, A. Hüttemann, J. McKitrick, H. Beebee, E. Tobin, L.A. Paul and J. Wilson in Mumford and Tugby (2013); H. Kincaid, P.Humphreys, A. Melnyk, D. Dennett, M. Wilson, M. Friedman and J. Ismael in Ross et al. (2013); M. O'Rourke, M.H. Slater, A. Borhini, P. Godfrey-Smith, N. Latham, R. Sorensen, A.C. Varzi, M. Devitt, B. Nany, N.E. Williams, B. Glymour, N. G. Rheins, J. K. Crane, R. Sandler and K. Vihvelin in Campbell et al (2011); S. Yudell, K. Brading, M. Strevens, C.K. Waters, K. Stanford, J. Saatsi and M. Thomas-Jones in Slater and Yudell (2017); Rescher (2000); Lowe (2006); Trout (2016).

${ }^{25}$ For a decisive criticism of Kitcher (1976, 1981), see Maxwell (1998, pp. 62-8).

${ }^{26}$ For a defence of scientific realism given the "optimistic induction" along these lines see Maxwell (1993a, 81-101) - a paper not referred to by Bishop (2003).

${ }^{27}$ See in particular Maxwell (1998, chs. 3-5 and pp. 211-2; 2004, appendix).

${ }^{28}$ There is also an extended discussion of dispositional realism but no reference to Maxwell (1968a), which may be said to have initiated the recent discussion of this view.

${ }^{29}$ For the detailed development of this view, see Maxwell (1968a). For slight modifications, see Maxwell (1993, pp. 81-101; 1998, pp. 141-155). Neither Ellis (2001) nor Bird (2007), both of whom defend a somewhat similar view, refer to Maxwell (1968a). It would seem to me that the first demonstration of the possibility, the intelligibility, of the existence of (analytically) necessary connections between successive states of affairs in nature should not be so quickly forgotten. Especially as it justifies construing theoretical physics as seeking to 
discover necessitating properties of things, properties (we may conjecture) that everything has in common with everything else. As it happens, Alexander Bird is aware of Maxwell (1968a); it was that paper that prompted him to work on the subject in the first place (personal communication). But because he ignores the paper, he fails, in his 2007 book, to exploit Maxwell's solution to the problem of how laws can be (analytically) necessary and theories fully contingent. As a result, Bird is forced to hold that laws have metaphysical necessity - a dubious notion of necessity lurking, supposedly, between contingency and logical necessity. And Ellis is in exactly the same boat: see Ellis (2001, ch. 7).

${ }^{30}$ Maudlin (2007) is also concerned with such matters as the nature of laws, counterfactuals, ontology and explanation but, like other writers on these topics, Maudlin ignores Maxwell (1968a) - as do most authors writing on the subject, from Tooley (1977) and Armstrong (1978; 1983) onwards.

${ }^{31}$ Mumford and Tugby (2013, introduction) come closest to recognizing this crucial point.

${ }^{32}$ For further discussion of Maxwell's work on AOE and the metaphysics of science, and its subsequent reception - or lack of it - see Maxwell (2019a).

${ }^{33}$ See Maxwell (1984 or 2007a). See also Maxwell (1976; 1992; 2000a; 2001, ch. 9; 2004a; 2007b; 2008; 2009a; 2012; 2013b; 2014a; 2016a; 2017a; 2017b; 2017c; 2019c).

${ }^{34}$ Bereft of such public education, as at present, there is always the danger that democracies will become dysfunctional, as illustrated recently by Brexit and the election of President Trump.

${ }^{35}$ To be fair, Maxwell's work has received some critical attention: see Maxwell (2007a, ch. 13); Muller (2008) and the response Maxwell (2009); McHenry (2009); Vicente (2010), Pandit (2010), and the response Maxwell (2010). See also works referred to in note 23. ${ }^{36}$ Matthew Tugby has suggested a rather more mundane reason for the neglect of AOE (personal communication). It is due to the fact that Maxwell has not attended the workshops attended by those working on the metaphysics of science. Published papers and books don't communicate ideas in the philosophy of science. This is done in workshops, in other words. ${ }^{37}$ See, for example, Maxwell (2019b).

${ }^{38}$ For the most recent and best exposition of this point see Maxwell (2017a, 60-64 and 103120).

${ }^{39}$ Maxwell (2017a, 112-120).

${ }^{40}$ Maxwell (2017a, 71-4). 